
Cavendish Laboratory, Cambridge: The Austin
Wing

Is 1936, the gift by the late Sir Herbert (afterwards Lord) Austin was announced of a sum of approximately 2250,000 for the work of the Cavendish Laboratory at Cambridge (see Nature, 137, 765; 1936). This enabled the University to proceed with ascheme of reconstruction of some of the laboratories, including a new building for the Cavendish Laboratory on the site of the old Zoological Laboratory. An imposing building, known as the Austin Wing, was erected in due course, and immediately taken over by the Government for war-time investigations. Now it has been released for its proper use, and was formally opened by Sir John Anderson on July 24. The Physical Society was holding an international conference, which was attended by seventy-five foreign guests, on "Fundamental Particles and Low Temperatures" in Cambridge during July 22-27, and the opening of the Austin Wing in the middle of the week fitted appropriately into the general programme.

The whole of July 24 was devoted to the Cavendish Laboratory; during the morning, papers dealing with current work in the Laboratory were read by E. S. Shire on nuclear physics, by W. 'H. Taylor on the X-ray analysis of various kinds of matter, by J. A. Ratcliffe on the work on radio carried out in the Cavendish and its outlying stations, by E. Orowan on the physics of metals, and by J.F. Allen on the Royal Society Mond Laboratory and its work on helium II and on magnetic phenomena. In the afternoon, a general meeting, under the chairmanship of the Vice-Chancellor of the University, was held in the Examination Hall; some four hundred delegates attending the Conference and members of the staff of the Cavendish Laboratory were present. Prof. J. D. Cockcroft gave a short history of the Austin gift and of the new building, after which the Vice-Chancellor introduced Sir John Anderson. Sir Lawrence Bragg thanked Sir John for his address, and presented him with a key with which to open the new building. After the formal opening, an inspection was made of the work in progress in the Austin Wing, the High Tension Laboratory and the Royal Society Mond Laboratory.

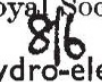

Hydro-electric Power and its Utilization

IN these days when the world is talking of power from fissionable moter, one is apt to forget the inexhaustible nd $x_{1} \mathrm{H}_{\text {of }}$ hydro-power. Hydro-power remains the day source of solar energy in which Napure holy seems prepared to undertake the tedibuf task of concentration; but the civil engineering 4 prks-dams, intakes, pipe-lines, canals and power-stations--are themselves engineering works of major importance. It already plays an important part in the industrial economy of the United States of America, where nearly half the potential sources are already tapped. Similar developments are impossible in Great Britain; catchment areas are too small, or they are too near sea-level. As our power-consuming processes expand, it is inevitable that they must be moved to areas where power now flows unharnessed. Except for the United States, only a tiny fraction of world-power is at present utilized ; much is, of course, in places remote from industrial regions, but half the world is now within one-day journey, and fear of isolation need no longer deter labour from migration. It seems that big fields are open to those specializing in the design and construction of hydro-plant, and that a subsequent export trade of considerable magnitude would accrue to the country responsible for building the plant.

Anticipating a demand for suitably trained engineers, the English Electric Co., Ltd., under the chairmanship of Sir George Nelson, is actively stimulating the post-graduate study of hydro-power. Appropriate courses of advanced lectures and training in laboratory technique have been arranged at the Imperial College of Science and "Technology in connexion with the Hawksley Hydraulic Laboratory under the direction of Prof. C. M. White, recently appointed to the new chair of fluid mechanics and hydraulic engineering. The English Electric Co. has placed the specialized knowledge of its technical staff at the disposal of the College and is contributing experimental equipment as well as a sum of $£ 10,000$ towards the initial expenses. The courses are open to students with honours degrees in engineering, and the subjects include fluid mechanics, river mechanics, model technique, hydraulic machines, hydrology, soil mechanics and concrete technology, together with their application to the design of the relevant hydraulic structures. Six English Electric bursaries of $£ 200$ a year are to be offered annually as an inducement to students who otherwise might hesitate to prolong an already long training; and various researches in progress in the laboratory at the outbreak of war are to be started again when students of the right type become available. Unfortunately, in this connexion much delay must result from the ruling of the Ministry of Education as to how entrants to the universities are to be selected.

\section{A Second Giant Sunspot}

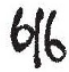

For the second time this year, an exceptionally large sunspot has appeared. Coming over the sun's eastern linfo puly 19-20, the centre of this giant spot cyof a the central meridian on July 26-28 (ppis sthy. $17^{\circ}$ north of the centre of the disk) and was difoto reach the western limb on August 2. In structure the spot is complex with several nuclei, and its area up to July 27 hovered around 4,000 millionths of the sun's hemisphere. Its predecessor in February had a mean area of about 4,300 millionths and a maximum area of 4,900 millionths-the largest sunspot group ever recorded at Greenwich.

A number of radio fade-outs on short-wave longdistance communication have been reported by Cable and Wireless Ltd. since July 20, and in several cases synchronous solar flares were observed in $6563 \mathrm{~A}$. $(H \alpha)$ at Greenwich and elsewhere. By far the most notable of these dual phenomena to date (July 27) was an intense solar flare commencing shortly after 16h. U.T. on July 25 and a long-continued fade-out beginning at $16 \mathrm{~h} .15 \mathrm{~m}$. This intense flare was observed at the Solar Physics Observatory, Cambridge, and by Dr. M. A. Ellison at Sherborne using his combined spectrohelioscope and spectrograph. The position of the flare, closely associated with the sunspot, was about $15^{\circ}$ east of the central meridian and $29^{\circ}$ from the centre of the disk, that is, within the central region of the disk known statistically to be favourable for a geomagnetic storm to occur about 24 hours after an intense flare. Ellison's observations indicate that the peak brilliancy was at about $16 \mathrm{~h} .29 \mathrm{~m}$., when the hydrogen line, $H \alpha$, in emission, had the abnormal width of $18 \mathrm{~A}$. The aggregate area of the flare filaments was half that of the sunspot itself. The helium line, $D_{3}$, was also 